\title{
ABSTRACTS OF THESES
}

\section{P. J. Lorimer, A Study of $\mathrm{T}_{2}$-Groups, McGill University}

(Supervisor: H.W.E. Schwerdtfeger).

In the past few years, the literature has contained a number of group-theoretic characterisations of the groups $\operatorname{PLF}(2, F)$, of Moebius transformations over a finite field $F$. The concept of a $\mathrm{T}_{2}$-group, defined by Professor H.W.E. Schwerdtfeger, gives a characterisation which is simpler than those previously given.

A group $G$ is called a $\mathrm{T}_{2}$-group if it contains a subgroup $\mathrm{H}$ and

(i) $a \notin \mathrm{H}, \mathrm{bab}^{-1} \notin \mathrm{H}$, and $\mathrm{a}^{2} \neq 1 \Rightarrow \exists$ unique $\mathrm{h} \in \mathrm{H} \rightarrow \mathrm{hah}^{-1}=b a b^{-1}$.

(ii) $a \notin \mathrm{H}, \mathrm{bab}^{-1} \& \mathrm{H}$, and $\mathrm{a}^{2}=1 \Rightarrow \exists$ exactly two elements $h_{1}, h_{2} \in H \quad h_{1} a h_{1}^{-1}=h_{2} a h_{2}^{-1}=b a b^{-1}$.

A $\mathrm{T}_{2}$-group $\mathrm{G}$ is called an $\mathrm{S}_{2}$-group if $\mathrm{G}-\mathrm{H}$ contains an involution, i.e. condition (ii) is not empty.

The following are $\mathrm{S}_{2}$-groups:

(1) $G=(0,1)^{\alpha}$ where $(0,1)$ is the group with two elements, and $\alpha$ is any cardinal number. $H$ is any subgroup of $G$ which is isomorphic to $(0,1)$.

(2) $\mathrm{H}$ is any Abelian group with exactly one involution and $\mathrm{G}$ is obtained from $\mathrm{H}$ by adjoining an element $t$ which obeys the laws, $t^{2}=1 ; t h t^{-1}=h^{-1}$ for all $h \in H$.

(3) $G=\operatorname{PLF}(2, F)$, where $F$ is a field of characteristic $\neq 2$, and $H$ is the subgroup of all similarities $z \rightarrow \frac{a z+b}{d}$.

The following theorems are proved:

THEOREM 1. If $\mathrm{G}$ is an $\mathrm{S}_{2}$-group, and either

(i) The subgroup $H$ is normal in $G$, or

(ii) The centre of $G$ is non-trivial,

then $G$ and $H$ are the group and subgroup of either (1) or (2).

THEOREM 2. If $G$ is a finite $S_{2}$-group and either

(i) The subgroup $H$ is not normal in $G$, or

(ii) The centre of $G$ is trivial,

then $G$ and $H$ are the group and subgroup of (3).

Thus all finite $\mathrm{S}_{2}$-groups are known; they are given by (1), (2), or (3), and Theorem 2 gives a characterisation of the groups $\operatorname{PLF}(2, F)$, when $F$ is finite and the characteristic of $F$ is not equal to 2 . 